\title{
An observational study of community health care nurses' knowledge about delirium
}

This article was published in the following Dove Press journal:

Nursing: Research and Reviews

29 March 2017

Number of times this article has been viewed

\author{
Rachid Akrour' \\ Henk Verloo ${ }^{2}$ \\ 'Department of Geriatric \\ Rehabilitation, Lausanne University \\ Hospital, Lausanne, ${ }^{2}$ Department \\ of Nursing Sciences, University of \\ Applied Sciences and Arts Western \\ Switzerland, Sion, Switzerland
}

Correspondence: Rachid Akrour Department of Geriatric Rehabilitation, Lausanne University Hospital, Avenue Pierre Decker 5, Lausanne CH-IOII, Switzerland

Tel +4I $79556 I 453$

Fax +4I 2I 3|4 I5 6I

Email rachid.akrour@chuv.ch
Background: Early detection of delirium among home-dwelling older patients is a substantial challenge for home health care providers. Despite an abundance of literature, recent studies still describe a widespread lack of knowledge about delirium and its underdetection in all types of health care settings.

Aims and objectives: This study aimed to assess the knowledge of community health care nurses (CHNs) about delirium in the Switzerland's French-speaking region.

Methods: A cross-sectional observational study involving $75 \mathrm{CHNs}$ was conducted between February and July 2015. Data were collected using an autoadministered questionnaire based on the study by Malenfant and Voyer, exploring theoretical knowledge of delirium and its detection using clinical vignette case studies. Outcomes were analyzed using descriptive statistics.

Results: Forty-eight CHNs participated in the study; nearly all of them $(44 ; 94 \%)$ selected the correct definition of delirium, and most $(36 ; 78 \%)$ knew its four principal diagnostic criteria. Only $16(34 \%)$ participants selected the confusion assessment method (CAM) as the recommended best practice delirium detection tool. Only 19 (40\%) and 23 (49\%) participants were able to correctly identify hypoactive and hyperactive delirium, respectively, from the clinical vignette case studies. The average score of CHNs on the Malenfant and Voyer's questionnaire was 12.7 (SD 3.2).

Conclusion: Participants showed moderate-to-low knowledge about delirium. The study identified a lack of knowledge on how to recognize the signs and symptoms of delirium and the absence of suitable delirium detection tools.

Keywords: delirium knowledge questionnaire, geriatric syndromes, delirium detection tools, clinical vignettes

\section{Background}

The majority of home-dwelling older adults wish to continue living in their own homes for as long as possible, even once they may need significant health care; this is widely encouraged by the Swiss health care system. ${ }^{1,2}$ Delirium is recognized as a devastating geriatric syndrome (GS) and should be considered as a significant challenge to community health care nurses (CHNs). ${ }^{3}$ Moreover, from one-third to half of older adults discharged from hospitals failed to have their delirium symptoms identified or recognized. ${ }^{4,5}$ It is well documented that patients with delirium have a greater risk of developing frailty and irreversible cognitive impairment, being institutionalized and premature death. ${ }^{6-8}$ The literature shows that nonpharmacological nursing strategies are recommended as the gold standard for the prevention of delirium. ${ }^{9}$ Recent studies among frontline hospital nurses showed that they were failing to detect 
delirium, specifically when it manifested as hypoactive delirium. ${ }^{10,11}$ Approximately $76 \%$ of people living in their homes and supported by community health care services (CHSs) are ${ }^{3} 65$ years old. Half of them are suffering from multimorbidity and GSs made up of physical, mental and/ or cognitive disorders. ${ }^{12}$ GSs such as delirium, instability, incontinence and frailty - all of which are highly prevalent among older home-dwelling older adults $>75$ years old and in declining health - determine the clinical competencies and knowledge that $\mathrm{CHNs}$ need to provide for an effective geriatric care. These GSs are mostly multifactorial and associated with high rates of morbidity in addition to the negative outcomes possible when older adults continue to live in their homes. ${ }^{13}$ Well-managed nursing care provided by CHNs using evidence-based practice is essential to prevent or stabilize GSs and functional decline and avoid hospitalization or institutionalization. ${ }^{14,15}$ Despite the availability of information, different authors have reported CHNs' lack of knowledge about delirium, its risk factors and its detection. ${ }^{16-18}$ Indeed, half of delirium cases in the community are not detected by CHNs due to their lack of knowledge about its etiology, signs and symptoms and the detection tools at their disposal. ${ }^{19}$ The present study adopted the definition and diagnostic criteria of delirium of the Diagnostic and Statistical Manual of Mental Disorders, Fifth Edition $(D S M-V) .{ }^{20}$ There is a paucity of studies that have explored the knowledge of delirium among CHNs.

This study aimed to explore the knowledge of CHNs about the delirium syndrome and its components and analyze the associations between knowledge about delirium's components and participants' sociodemographic and professional characteristics.

\section{Methods}

\section{Study design}

A cross-sectional descriptive study was undertaken using an email questionnaire to assess eligible participants' knowledge about the detection, recognition, assessment and clinical features of delirium.

\section{Sample}

The study's eligible population was composed of 75 frontline CHNs carrying out clinical activities with home-dwelling older adults under the responsibility of a single regional home health care center (HCC) comprising six operational CHN teams. In collaboration with their HCC supervisors, researchers selected eligible participants based on their availability during the research period. Exclusion criteria were: 1) CHNs not active as frontline nurses; 2) temporary $\mathrm{CHNs}$ hired for less than 3 months; and 3) student CHNs.

\section{Data collection}

The Home Healthcare Centre's Internal Committee on Research Involving Humans had previously approved the study on November 20, 2014. Data collection started on February 15 and was completed on July 15, 2015. The study nurse announced the survey by email 1 week before its launch. All eligible $\mathrm{CHNs}$ were invited to participate by the HCC's management, and those who became involved gave their written consent. The supervisor of the operational CHN teams sent reminders by email after 2, 4 and 6 weeks.

\section{Assessment of knowledge and recognition of delirium}

Data were collected using Malenfant and Voyers ${ }^{19}$ questionnaire, culturally adapted to French-speaking Switzerland and based on the delirium, dementia and depression guidelines of the Registered Nurses Association of Ontario. ${ }^{21}$ In a previous study, the questionnaire demonstrated good psychometric properties, particularly regarding internal consistency, showing a Cronbach alpha of $0.84 .^{22}$

Participants were assessed on their knowledge of delirium and their clinical ability to recognize it. Knowledge of the definition and description of delirium was assessed based on eight keywords. Knowledge was assessed based on the four basic diagnostic criteria, delirium detection tools and the clinical signs and symptoms of hyperactive delirium, hypoactive delirium and delirium superimposed on dementia using five clinical vignette case studies involving home-dwelling older adults. A high score of 24 indicated excellent knowledge about delirium, and a score of 0 meant no knowledge about the syndrome. An average time of 15 minutes was needed to complete the questionnaire.

\section{Statistical analysis}

Answers were scored as proposed by Malenfant and Voyer. ${ }^{19}$ Parametric tests were applied to normally distributed variables; nonparametric tests were preferred in cases of abnormal distributions. One questionnaire with $<50 \%$ of the items completed was excluded. The random pattern of the missing values in surveys that were $\geq 50 \%$ complete allowed multiple imputations to replace missing data. These incomplete questionnaires were treated using SPSS multiple data input and completed using an attrition analysis. ${ }^{23}$ Data were analyzed using SPSS software version 22.0, and the statistical significance level was set at $p<0.05 .^{23}$ 


\section{Results}

\section{Sample}

A total of 48 of 75 CHNs responded to the questionnaire, corresponding to a $64 \%$ response rate. One questionnaire that was $<50 \%$ complete was excluded; thus, 47 questionnaires were analyzed (Figure 1). Data were normally distributed, except for sex. The attrition rate of $35.4 \%$ was acceptable for an email survey. ${ }^{24,25}$

\section{Sociodemographic and professional characteristics}

The sample of CHNs was mainly composed of women (86\%), and the approximate average age was 40 years old (range, 22-64). Professional experience varied between 3 months and 44 years, with a mean of 14 years; the average length of experience in geriatrics was approximately 5 years. Thirty-nine participants (90.7\%) reported that they had never had any specific training on the delirium syndrome. Table 1 presents the participants' sociodemographic and professional characteristics.

\section{Knowledge of delirium}

\section{Diagnostic criteria}

Nearly all the participants $(44 ; 93.6 \%)$ selected the correct definition of delirium from the three choices proposed (Table 2, a). Almost half of the participants (n 20; 42.5\%) were able to identify all four diagnostic criteria for delirium (Table 2, b). However, the fluctuating state of cognition was less frequently selected. Few recognized the main delirium signs and symptoms. Eight CHNs (17.0\%) confused the signs and symptoms of dementia with those of delirium, and 10 participants $(21.2 \%)$ confused them with those of depression (Table 2, c).

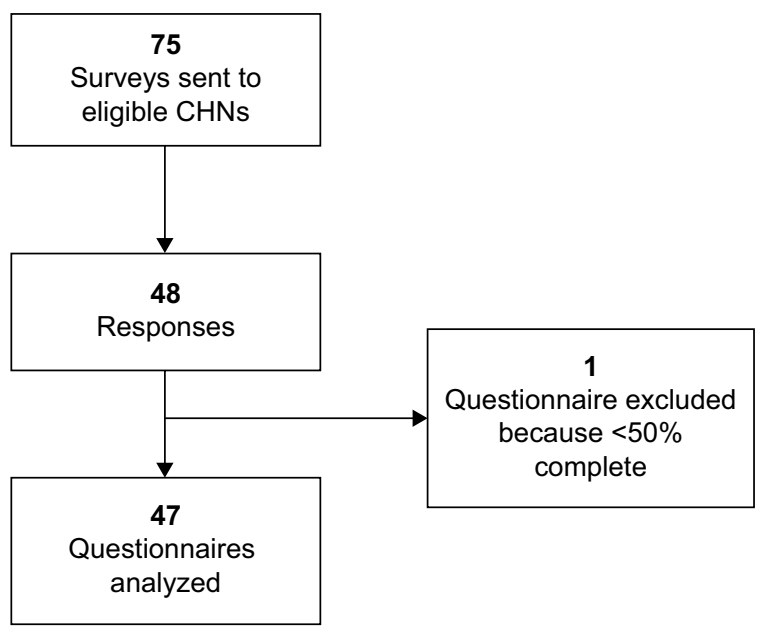

Figure I Data collection procedure. Abbreviation: $\mathrm{CHN}$, community health care nurse.
Table I Sociodemographic and professional characteristics of the CHNs $(\mathrm{N}=47)$

\begin{tabular}{ll}
\hline Characteristics $(\mathbf{n}=\mathbf{4 3})$ & \\
\hline Age, mean (SD) & $39.4(10.2)$ \\
Female, $n(\%)$ & $37(86.0)$ \\
Highest diploma obtained, $n(\%)$ & \\
$\quad$ Swiss bachelor's degree & $7(16.2)$ \\
UAS + registered nurses & $5(11.7)$ \\
Foreign registered nurses & $31(72.1)$ \\
$\quad$ Nurses with master's degree & $0(0.0)$ \\
Delirium education, $n$ (\%) & $4(9.3)$ \\
Years of nursing experience, mean (SD) & $14.4(9.3)$ \\
Years of experience in CHC, mean (SD) & $5.8(4.7)$ \\
Years of geriatric experience, mean (SD) & $4.6(6.4)$ \\
\hline
\end{tabular}

Abbreviations: $\mathrm{CHN}$, community health care nurse; UAS, University of Applied Sciences; CHC, community health care; SD, standard deviation.

\section{Detection and signs and symptoms of delirium in clinical vignette case studies}

None of the participants managed to correctly select the right 8 signs and symptoms of delirium from the 12 proposed (Table $2, \mathrm{c})$. One-third of the CHNs (n 16;34.0\%) correctly selected the confusion assessment method (CAM) as a tool for delirium detection from the seven tools proposed (Table 3). Less than half of the CHNs (n 19; 40.4\%) detected hypoactive delirium in clinical vignette cases studies, whereas almost two-thirds of them (n 23; 48.9\%) detected the hyperactive form. Delirium superimposed on dementia was detected by 20 CHNs (42.5\%) (Table S1). The majority of participants (n $31 ; 63.7 \%$ ) chose the correct definition of the signs and symptoms of delirium (Table 2). Nine participants (19.1\%) correctly selected the definition of disorganized thinking. The CHNs' average total score for knowledge about delirium was 12.7 (SD 3.2) out a possible 24 . This average score was only reached by half of the participants (n 25), reflecting a moderate overall level of knowledge regarding delirium (Table 4). The questionnaire's Cronbach alpha coefficient was 0.70 , which is considered to be an acceptable level of internal consistency. ${ }^{22,26}$

\section{Correlation between knowledge about delirium and sociodemographic and professional characteristics}

No statistically significant correlations were found between the components of knowledge about delirium and the sociodemographic and professional characteristics of the participants (Table S2).

\section{Discussion}

This survey explored CHNs' knowledge about delirium in the French-speaking part of Switzerland. It showed that they 
Table 2 Responses on the definition and diagnostic criteria of delirium $(\mathrm{N}=47)$

\begin{tabular}{|c|c|}
\hline & n (\%) \\
\hline \multicolumn{2}{|l|}{ a. What is the definition of delirium? $(N=47)$} \\
\hline $\begin{array}{l}\text { Permanent mental disorder with a progressive onset of } \\
\text { cognitive impairment, disorientation in time and space, } \\
\text { dysfunction of attention, a decline of consciousness and } \\
\text { perception disorders }\end{array}$ & $\mathrm{I}(2 . \mathrm{I})$ \\
\hline $\begin{array}{l}\text { Fluctuating temporary mental disorder with a sudden } \\
\text { cognitive impairment onset, disorientation and } \\
\text { dysfunction of the attention, a declining consciousness } \\
\text { level and perception disorders }\end{array}$ & $44(93.6)$ \\
\hline $\begin{array}{l}\text { Chronic disease is becoming more common in older } \\
\text { people. In general, it affects memory and mental faculties. } \\
\text { Delirium evolves gradually and irreversibly due to a } \\
\text { degeneration of brain tissue, leading to dementia }\end{array}$ & $2(4.2)$ \\
\hline $\begin{array}{l}\text { b. What are the diagnostic criteria used by physicians to } \\
\text { make a delirium diagnosis? }(\mathrm{N}=47)\end{array}$ & \\
\hline $\begin{array}{l}\text { Disturbance of consciousness (reduction of a clear } \\
\text { awareness of the environment) with reduced ability to } \\
\text { direct, focus, sustain or shift attention }\end{array}$ & $43(91.4)$ \\
\hline $\begin{array}{l}\text { Rapid symptoms onset (hours or days) and fluctuation } \\
\text { during the day }\end{array}$ & $42(89.3)$ \\
\hline $\begin{array}{l}\text { Chronic disease is becoming more common in older } \\
\text { people. In general, it affects memory and mental faculties. } \\
\text { Delirium evolves gradually and irreversibly due to a } \\
\text { degeneration of brain tissue, leading to dementia }\end{array}$ & $4(8.5)$ \\
\hline $\begin{array}{l}\text { Inability to learn new information, to remember } \\
\text { information previously acquired }\end{array}$ & $25(53.1)$ \\
\hline $\begin{array}{l}\text { Change in cognition (memory deficit, disorientation or } \\
\text { language difficulty), difficulty of perception not related to } \\
\text { preexisting stabilised or evolving dementia }\end{array}$ & $4 \mid(87.2)$ \\
\hline $\begin{array}{l}\text { Markedly diminished interest or pleasure in all or almost } \\
\text { all activities throughout the day, nearly every day (by } \\
\text { subjective account or observation made by others) }\end{array}$ & $13(27.6)$ \\
\hline Insomnia and hypersomnia nearly every day & $14(29.7)$ \\
\hline $\begin{array}{l}\text { Evidence from the history of the disease, physical } \\
\text { examination or laboratory examinations, the symptoms } \\
\text { are the direct physiological consequence of a general } \\
\text { medical condition (physical cause, intoxication, } \\
\text { medication, etc.) }\end{array}$ & $20(42.5)$ \\
\hline $\begin{array}{l}\text { c. Select the essential signs and symptoms of delirium } \\
\qquad(N=47)\end{array}$ & \\
\hline Loss of interest or pleasure in normal activities & $10(21.2)$ \\
\hline Apraxia & $8(17.0)$ \\
\hline Inattention & $35(74.4)$ \\
\hline Aphasia & $15(31.9)$ \\
\hline Fluctuating mental and/or motor symptoms & $22(46.8)$ \\
\hline Significant weight loss or weight gain & $I(2.1)$ \\
\hline Rapid onset of mental and/or motor symptoms & $24(51.0)$ \\
\hline Continuous cognitive decline & $8(17.0)$ \\
\hline Altered level of consciousness & $33(70.2)$ \\
\hline Suicidal ideation & $\mathrm{I}(2.1)$ \\
\hline Disruption of long-term memory & $4(8.5)$ \\
\hline Impaired cognition and/or perceptual disturbances & $39(82.9)$ \\
\hline
\end{tabular}

had a moderate-to-low level of knowledge about delirium, corroborating previous findings by Malenfant and Voyer. ${ }^{19}$ Most surprising was participants' poor knowledge about
Table 3 Responses on detection tools for delirium $(\mathrm{N}=47)$

\begin{tabular}{ll}
\hline Tools & $\mathbf{n}(\%)$ \\
\hline MMSE & $23(48.9)$ \\
VAS & $0(0.0)$ \\
DRS & $5(10.6)$ \\
CGA & $3(6.4)$ \\
NCS & $5(10.6)$ \\
GDS & $3(6.4)$ \\
CAM & $16(34.0)$ \\
\hline
\end{tabular}

Abbreviations: MMSE, Mini-Mental State Examination; VAS, visual analogue scale; DRS, dementia rating scale; CGA, comprehensive geriatric assessment; NCS, Neecham confusion scale; GDS, geriatric depression scale; CAM, Confusion assessment method.

Table 4 Summary of questionnaire scores $(N=47)$

\begin{tabular}{lllll}
\hline Questionnaire variables & Mean & SD & Min & Max \\
\hline Definition of delirium $^{\mathrm{a}}$ & 0.9 & 0.2 & 0 & $\mathrm{I}$ \\
Diagnostic criteria of delirium $^{\mathrm{b}}$ & 3.1 & 0.6 & 2 & 4 \\
Signs and symptoms of delirium $^{\mathrm{c}}$ & 2.3 & 1.5 & 0 & 5 \\
Definition of signs and symptoms of & 5.0 & 1.8 & $\mathrm{I}$ & 8 \\
delirium $^{\mathrm{d}}$ & 0.9 & 0.5 & 0 & 3 \\
Delirium detection tools $^{\mathrm{e}}$ & 1.4 & 1.1 & 0 & 3 \\
Clinical vignette case studies $^{\mathrm{f}}$ & 12.7 & 3.2 & 6 & 19 \\
Total points for the questionnaire $^{\mathrm{g}}$ &
\end{tabular}

Notes: amaximum score for the question I. bMaximum score 4. 'Maximum score 5. 'Maximum score 8. ${ }^{\mathrm{e}}$ Maximum score 3. 'Maximum score 3. 8 Maximum total questionnaire score 24.

Abbreviations: min, minimum; max, maximum; SD, standard deviation.

the fluctuation of cognition being a major clinical sign of delirium. This means that CHNs have not integrated the clinical warning sign of fluctuations in cognition as an alert to help them detect delirium when visiting home-dwelling older adults. This reinforces the risk of an underdetection of delirium among this group, a situation already well documented in a plethora of scientific publications concerning acute hospital settings. ${ }^{27,28}$

Furthermore, CHNs showed a lack of knowledge about tools available for the detection of delirium, further increasing the risks of failing to detect it in home-dwelling older adults during a typical comprehensive geriatric assessment. ${ }^{19}$ The repercussions of this could be an inability to differentiate between the clinical assessments of different mental disorders or even no assessment at all due to a failure to correctly identify delirium, especially in its clinical hypoactive form affecting the noncommunication of delirium symptoms and sign between nurses and the family physician. ${ }^{10,18,29-31}$

Consequently, CHNs do not always seem to be aware of the specific clinical manifestations of the syndrome occurring during episodes of delirium. Not detecting delirium delays the implementation of a patient-centered intervention strategy for the causal factors of the syndrome and could be an 
important barrier to physicians delivering a rapid diagnosis of delirium. This corroborates the findings of Han et al, ${ }^{32}$ which demonstrated a high occurrence of delirium among older adults admitted to an emergency department.

The present study confirmed that CHNs had difficulties detecting delirium among home-dwelling adults, whether it was hyperactive, hypoactive or superimposed on dementia. This lack of knowledge about delirium could develop into a broader public health issue, as there are demonstrated associations between delirium and the risk of falls with hospitalization, frailty, institutionalization in long-term care settings, irreversible cognitive impairment and avoidable mortality among home-dwelling older adults. ${ }^{33,34}$

\section{Study strengths and limitations}

This study has both strengths and limitations. A first strength was the methodological rigor of the assessment of the knowledge about delirium and its detection among the participants. A second strength was the analytical strategy for dealing with missing values and the attrition rate. Limitations included the relatively small sample group and the fact that data were collected from a single regional community health care site. Thus, any generalization of these results should be made with caution.

\section{Conclusion}

This exploratory study identified a lack of basic knowledge about delirium among CHNs. This is relevant, not only as a geriatric health issue but also as a public health issue. The results corroborated other existing observational studies. Our findings highlight the need to deploy training strategies to increase clinical knowledge about delirium among CHNs. Additionally, our findings suggest that it would be important for any systematic and comprehensive geriatric assessment of home-dwelling older patients to integrate an assessment of delirium and its risk factors.

\section{Acknowledgments}

We thank the community health care nurses for their participation in this study. This work would not have been possible without the support of the departmental managements of Geneva Home Healthcare.

\section{Author contributions}

R Akrour and H Verloo contributed to study concept, data collection, data analysis and interpretation, manuscript drafting, statistical analysis, study supervision, and writing and revising the manuscript.

\section{Disclosure}

The authors report no conflicts of interest in this work.

\section{References}

1. Cavalli S. Vieillards à domicile, vieillards en pension: une comparaison. Suisse, Lausanne: Editions Réalités Sociales; 2002.

2. Laroque G. My house, my castel. Gérontol Soc. 2011;136(1):1-8.

3. Flaherty JHJ, Morley JEJ. Delirium: a call to improve current standards of care. J Gerontol A Biol Sci Med Sci. 2004;59(4):341-343.

4. Saczynski JS, Marcantonio ER, Quach L, et al. Cognitive trajectories after postoperative delirium. $N$ Engl J Med. 2012;367(1): 30-39.

5. Pitkala KH, Laurila JV, Strandberg TE, Tilvis RS. Prognostic significance of delirium in frail older people. Dement Geriatr Cogn Disord. 2005;19(2-3):158-163.

6. Brown CJ, Friedkin RJ, Inouye SK. Prevalence and outcomes of low mobility in hospitalized older patients. J Am Geriatr Soc. 2004; 52(8):1263-1270.

7. Zisberg A, Shadmi E, Sinoff G, Gur-Yaish N, Srulovici E, Admi H. Low mobility during hospitalization and functional decline in older adults. J Am Geriatr Soc. 2011;59(2):266-273.

8. Cole MG, McCusker J. Improving the outcomes of delirium in older hospital inpatients. Int Psychogeriatr. 2009;21(4):613-615.

9. Inouye SK, Westendorp RG, Saczynski JS. Delirium in elderly people. Lancet. 2014;383(9920):911-922.

10. Hamdan-Mansour AM, Farhan NA, Othman EH, Yacoub MI. Knowledge and nursing practice of critical care nurses caring for patients with delirium in intensive care units in Jordan. J Contin Educ Nurs. 2010; 41(12):571-576.

11. Christensen M. An exploratory study of staff nurses' knowledge of delirium in the medical ICU: an Asian perspective. Intensive Crit Care Nurs. 2014;30(1):54-60.

12. Geneva Institutions' of Home Healthcare. Home Care and Support Institution. Geneva: Geneva Institutions' of Home Healthcare (IMAD); 2014.

13. Inouye SK, Studenski S, Tinetti ME, Kuchel GA. Geriatric syndromes. J Am Geriatr Soc. 2007;55(12):2092-2093.

14. Buurman BM, Parlevliet JL, van Deelen BAJ, de Haan RJ, de Rooij SE. A randomised clinical trial on a comprehensive geriatric assessment and intensive home follow-up after hospital discharge: the Transitional Care Bridge. BMC Health Serv Res. 2010;10:296.

15. Soejono CH. The impact of 'comprehensive geriatric assessment (CGA)' implementation on the effectiveness and cost (CEA) of healthcare in an acute geriatric ward. Acta Med Indones. 2008;40(1):3-10.

16. Steis M, Fick DM. Are nurses recognizing delirium? A systematic review. J Gerontol Nurs. 2008;34(9):40-48.

17. Agar M, Draper B, Phillips PA, et al. Making decisions about delirium: a qualitative comparison of decision making between nurses working in palliative care, aged care, aged care psychiatry, and oncology. Palliat Med. 2012;26(7):887-896.

18. Demir Korkmaz F, Gok F, Yavuz Karamanoglu A. Cardiovascular surgery nurses' level of knowledge regarding delirium. Nurs Crit Care. 2016;21(5):279-286.

19. Malenfant $P$, Voyer P. Detecting delirium in older adults living at home. J Community Health Nurs. 2012;29(2):121-130.

20. American Psychiatric Association. Diagnostic and Statistical Manual of Mental Disorders (DSM-5®). Washington DC; American Psychiatric Publishing; 2013.

21. Registered Nurses Association of Ontario. Screening for Delirium, Dementia and Depression in Older Adults. Toronto: Registered Nurses Association of Ontario; 2016.

22. Cohen J. Statistical Power and Analysis for the Behavioral Sciences. 2nd ed. Hillsdale, NY: Lawrence Erlbaum Associates; 1988.

23. IBM-SPSS. Statistical Package for Social Sciences 22.0. Somer, NY: IBM Corporation; 2011. 
24. Kellerman SE, Herold J. Physician response to surveys. A review of the literature. Am J Prev Med. 2001;20(1):61-67.

25. Hummers-Pradier E, Scheidt-Nave C, Martin H, Heinemann S, Kochen MM, Himmel W. Simply no time? Barriers to GPs' participation in primary health care research. Fam Pract. 2008;25(2):105-112.

26. Bryman A. Barriers to integrating quantitative and qualitative research. J Mix Methods Res. 2007;1(1):8-22.

27. Lindner UK. Erkennen und verstehen Störungen: akute Verwirrung Als das primäre symptom. [Recognizing and understand disorders: acute confusion as the primary symptom]. Pflege Z. 2007;60(5): 288-289.

28. Voyer P, Richard S, McCusker J, et al. Detection of delirium and its symptoms by nurses working in a long term care facility. $J$ Am Med Dir Assoc. 2012;13(3):264-271.

29. Tippett V. Hypoactive delirium: assessing the extent of the problem. Palliat Med. 2007;21(2):161; author reply161-162.
30. Atanasova MP. Postoperative delirium, hyperactive and hypoactive type, after elective abdominal surgery, a challenge for the ICU staff. Anaesthesiol Intensive Care. 2012;41(3):3-6.

31. Detweiler MB, Kenneth A, Bader G, et al. Can improved intra- and inter-team communication reduce missed delirium? Psychiatr $Q$. 2014;85(2):211-224.

32. Han JH, Shintani A, Eden S, et al. Delirium in the emergency department: an independent predictor of death within 6 months. Ann Emerg Med. 2010;56(3):244-252.e1.

33. Fong TG, Davis D, Growdon ME, Albuquerque A, Inouye SK. The interface between delirium and dementia in elderly adults. Lancet Neurol. 2015;14(8):823-832.

34. Witlox J, Eurelings LSM, de Jonghe JFM, Kalisvaart KJ, Eikelenboom P, van Gool WA. Delirium in elderly patients and the risk of postdischarge mortality, institutionalization, and dementia: a meta-analysis. JAMA. 2010;304(4):443-451. 


\section{Supplementary materials}

Table SI Responses to the cases studies questions $(N=47)$

\begin{tabular}{|c|c|}
\hline Cases studies & n (\%) \\
\hline \multicolumn{2}{|l|}{ Case study I $(\mathrm{N}=47)$} \\
\hline Delirium & $19(40.4)$ \\
\hline Dementia & $2(4.3)$ \\
\hline Delirium superimposed on dementia & $6(12.8)$ \\
\hline Depression & $12(25.5)$ \\
\hline Cognitive impairment not attributable to any of these conditions & $8(17.0)$ \\
\hline Normal state & $0(0.0)$ \\
\hline \multicolumn{2}{|l|}{ Case study $2(N=47)$} \\
\hline Delirium & $3(6.3)$ \\
\hline Dementia & $2(4.2)$ \\
\hline Delirium superimposed on dementia & $I(2.1)$ \\
\hline Depression & $36(76.5)$ \\
\hline Cognitive impairment not attributable to any of these conditions & $5(10.6)$ \\
\hline Normal state & $0(0.0)$ \\
\hline \multicolumn{2}{|l|}{ Case study $3(N=47)$} \\
\hline Delirium & $23(48.9)$ \\
\hline Dementia & $6(12.7)$ \\
\hline Delirium superimposed on dementia & $6(12.7)$ \\
\hline Depression & $0(0.0)$ \\
\hline Cognitive impairment not attributable to any of these conditions & $12(25.5)$ \\
\hline Normal state & $0(0.0)$ \\
\hline \multicolumn{2}{|l|}{ Case study $4(N=47)$} \\
\hline Dementia & $13(27.6)$ \\
\hline Delirium & $4(8.5)$ \\
\hline Delirium superimposed on dementia & $20(42.5)$ \\
\hline Depression & $0(0.0)$ \\
\hline Cognitive impairment not attributable to any of these conditions & $10(21.2)$ \\
\hline Normal state & $0(0.0)$ \\
\hline \multicolumn{2}{|l|}{ Case study $5(\mathrm{~N}=47)$} \\
\hline Delirium & $\mathrm{I}(2.1)$ \\
\hline Dementia & $24(51.0)$ \\
\hline Delirium superimposed on dementia & $5(10.6)$ \\
\hline Depression & $\mathrm{I}(2.1)$ \\
\hline Cognitive impairment not attributable to any of these conditions & $12(25.5)$ \\
\hline Normal state & $4(8.5)$ \\
\hline
\end{tabular}

Table S2 Correlation matrix by sociodemographic variable and total score for delirium knowledge

\begin{tabular}{llllllll}
\hline Variables & $\mathbf{I}$ & $\mathbf{2}$ & $\mathbf{3}$ & $\mathbf{4}$ & $\mathbf{5}$ & $\mathbf{6}$ \\
\hline Age & 0.32 & 0.16 & 0.06 & 0.14 & 0.15 & $0.04^{*}$ & 0.15 \\
Nursing experience & 0.31 & 0.13 & 0.12 & 0.09 & 0.19 & 0.15 & 0.12 \\
Community Healthcare experience & 0.22 & 0.16 & 0.27 & 0.06 & $0.02^{*}$ & 0.26 & 0.10 \\
Geriatric experience & 0.22 & $0.00^{*}$ & 0.07 & 0.05 & 0.14 & 0.10 & $0.03^{*}$ \\
Diploma & 0.42 & 0.49 & 0.61 & 0.28 & 0.74 & 0.14 & 0.41 \\
Continuing training & 0.13 & 0.19 & 0.10 & 0.17 & 0.11 & 0.29 & 0.24 \\
Continuing training in aging & 0.05 & $0.01^{*}$ & 0.27 & 0.09 & 0.10 & 0.09 & 0.05 \\
\hline
\end{tabular}

Notes: I) Delirium definition score; 2) delirium diagnostic criteria score; 3) signs and symptoms of delirium score; 4) definition of signs and symptoms of delirium score; 5) detection tools for delirium score; 6 ) cases studies score; 7) total score questionnaire. *Correlation is significant at $p=<0.05$. 


\section{Publish your work in this journal}

Nursing: Research and Reviews is an international, peer-reviewed, open access journal publishing original research, reports, reviews and commentaries on all aspects of nursing and patient care. These include patient education and counseling, ethics, management and organizational issues, diagnostics and prescribing, health outcomes, economics and resource management, improving patient safety in all settings. The manuscript management system is completely online and includes a very quick and fair peer-review system. Visit http://www.dovepress com/testimonials.php to read real quotes from published authors.

Submit your manuscript here: https://www.dovepress.com/nursing-research-and-reviews-journal 